Open Access

\title{
Children born in July and August: a study on the age regulation in primary school and student's education access and development
}

\author{
Dehuan Liu ${ }^{1 *}$ and Xuelian $\mathrm{Li}^{2}$
}

\author{
* Correspondence: liudehuan@vip. \\ sina.com \\ ${ }^{1}$ Peking University School of New \\ Media, Peking University, No.5 \\ Yiheyuan Road Haidian District, \\ Beijing 100871, People's Republic of \\ China \\ Full list of author information is \\ available at the end of the article
}

\begin{abstract}
This paper discusses at the microlevel the educational inequality resulting from the cutoff birthdate regulation in the current primary school admission system. According to our research, among the students who enroll in school, students born in July and August display a relative disadvantage and adaptive difficulties in the construction of self-identity and study ability when compared with those born in September and October. Students born between November and June in the following year have mid-level performance. Moreover, this effect is accumulative. With regard to acquiring educational resources, students born in July and August show the lowest possibility of getting into the key senior middle schools, 16.7-22. $8 \%$ lower than the rest of the student population, while the possibility of being admitted to vocational school is the highest, 54.2-60.8\% higher than the others. This disadvantage is more prominent among male students. Our study also shows that the above effect is very strong and cannot be effectively suppressed by the socioeconomic factors. The "July/August pitfall" appears to be insurmountable.
\end{abstract}

Keywords: Educational equality, Youth, Relative age effect, Adaptive difficulties

\section{Cutoff birthday regulations: a struggle of policies and mentality}

In February 2015, Nanfang Daily conducted a survey on education. Nearly half of the respondents were curious about the feasibility of "flexible enrollment," in which August 31 would no longer be used as the cutoff date. In response, the director of the Guangdong Department of Education, Luo Weiqi, gave the following response: "With a new term starting on September 1st, it is a national practice that the cutoff be set at August 31st. If the calendar year, that is, December 31 used as the cutoff date, then the problem remains, except that Saggitarians instead of Virgos are affected. The deadline could be moved forward or back by a few days, but there has to be one" (Zhang and Leiyu 2015).

The 9-year compulsory education system adopted in 1986 provides children over age of six with a formal education. In practice, children who turn six before September each year are eligible to apply to school while those who turn six on or after September 1 have to apply the following year. This 1-year gap has drawn widespread attention from parents, especially to those whose child is born in September. A single-day

(c) 2016 The Author(s). Open Access This article is distributed under the terms of the Creative Commons Attribution 4.0 International License (http://creativecommons.org/licenses/by/4.0/), which permits unrestricted use, distribution, and reproduction in any medium, provided you give appropriate credit to the original author(s) and the source, provide a link to the Creative Commons license, and indicate if changes were made. 
difference in date of birth can mean an entire year of delayed enrollment. Many problems arise as a result. For instance, many mothers request cesarean section in August, and privileged families are allowed to cross over policy restraints, thus creating "grey areas." This struggle reflects the pursuit of equal education opportunities. These issues have resulted in appeals from the media and NPC delegates for more flexible enrollment. The education departments' response was that as long as a cutoff date exists, opportunity inequality will be present regardless of what changes are made.

Putting policy changes aside, the source of parents' anxiety lies in the conviction that children must not fall behind. In qualitative interviews, parents have expressed their belief that no one knows what the future will hold. Although it may appear to be a minor issue, enrollment 1 year earlier can mean no comprehensive tests or better economic conditions. It could mean that children will be studying with students in their own age even if they are held back. As one parent put it, "I get the feeling that our children are facing such great pressure that they cannot afford to waste a single day" (Li and Li 2013). In the face of such uncertainties, parents hope that their children will be given sufficient time and space to maneuver, but the accompanying risks that come along are severely underrated.

Does a year of delayed enrollment constitute a hindrance for children born in September and October? Is early enrollment really the optimal choice for the lucky ones born in July and August? The concern over this deadline comes as the result of high expectation for the youths' growth, but the real equality concerning youths' daily study lies covered and ignored.

Studying the age restrictions in the current system and its rationale from a research perspective should include investigating how the policy affects youth's learning and adaptability. Interest in this subject derives from a program from 2012 to 2014 when our team conducted surveys and analyses nationwide on teenagers' use of online games, their gaming psychology, and lifestyle. The study uncovered a very special group-those born in July and August. In the early stage of the online game life cycle, they manifested greater involvement in the games as compared with peers and exhibited notable differences in individual indexes. This led us to wonder if some particular social reality lay underneath or whether it was a mere data trap. The analysis of the data revealed no remarkable differences among children born in different months in terms of temperament, family income, parental occupation, or status. However, with a closer look at their daily behavior, differences started to emerge. Their frequent game playing and high level of dependence is the consequence of institutional influence. This paper sets out to uncover from a micro perspective where the influence comes from and how it operates.

The age restrictions under 9-year compulsory education have been implemented for nearly three decades, but no previous studies have attempted to explain the differences in youths' growth and development from this aspect. The constructive effect of such miniscule, seemingly unimportant but enduring policies tend to be neglected as compared with sudden and macroevents.

Thomas once discussed his view on social science studies by saying "The human wish underlies all social happenings and institutions, and human experiences constitute the reality beneath the formal social organization and behind the statistically formulated mass-phenomena" (Thomas 1988: 244). Taken in themselves, statistics are nothing 
more than symptoms of unknown causal processes. A social institution can be understood and modified only if we do not limit ourselves to the study of its formal organization but also to analyze the way in which it appears in the personal experience of various members of the group and follow the influence it has on their lives.

The formation of any stereotype or mentality has to do with the people's understanding of facts. This article thus focuses on how school-age groups adapt to school life in terms of the construction of self-identity and academic performance under the current system and seeks to explain differences in education acquisition and development in teenagers born in different months in order to challenge the stereotypes and to clarify the facts.

\section{Literature review and theoretical framework}

Youth development and access to education has always been the subject of global research, while open and fair access to education resources is deemed to be one of the hallmarks of social progress. Under the one-child policy, youth development and education, always at the heart of public attention, becomes even more relevant.

The relationship between social stratification and education fairness has been the subject of countless debates. In his social capital theories, Pierre Bourdieu emphasizes the significance of education as a means of transmission and reproduction of social capital. He believes that both favorable and adverse social factors shape the learning process greatly and accumulatively. These factors even influence our cultural life. "High social origins don't automatically and equally favor those who have the benefit of it" (Bourdieu and Passeron 2002: 33). Educational institutions, sometimes through logic features, perpetuate such privileges and serve the privileged in secrecy. The more equal opportunities appear to be, the more legitimized privilege is and the fuzzier the public perception of privilege. Bourdieu claims to admit innate differences in abilities but insists that "sociological studies should question and gradually reveal cultural inequalities caused by social restrictions in the guise of differing gifts. So long as there is an absence of in-depth research into ways unequal social factors come into play or an absence of educational efforts to overcome the influence of such social factors, it is better to doubt than to believe" (Bourdieu and Passeron 2002: 99).

However, the view taken toward education access and fairness directly determines how we consider the reason for differences and the approaches we take to address the issue. In reviewing past literature, the following research approaches and focuses are worth mentioning.

\section{Studies of education equality at macrolevel}

\section{Equal opportunities from the perspective of social stratification}

As two research approaches, ${ }^{1}$ Bourdieu's "network resource" and Coleman's "social closure" have long dominated the research field concerning social capital and education access, with the former emphasizing how resources hidden behind social networks influence education access and the latter stressing the support of closed networks (Zhao and Hong 2012). The two research perspectives above have a close connection with the discussion on education equality.

Based on Blau-Duncan's status attainment theory, a series of related studies on family social capital and children's education have been sparked under the wider framework of the 
influence of social stratification on children's attainment, including branch studies such as education access. Domestic studies have found that the influence from social background and social class exists all the time from 1978 to 2003 (Liu 2006). Based on the theoretical framework of intergenerational persistence of educational inequality, Li (2006) puts emphasis on the correlation between the mechanisms of educational inequality, institutional design and social background, and concludes that the resource advantages of the dominant class are slowly turning into better education opportunities for their children.

From the education supply perspective, Raftery and Hout (1993) propose "maximally maintained inequality" and expound on the connection between education expansion and education stratification in Ireland during the industrialization process. They point out that the benefits of expansion do not reach the bottom until the needs of the relatively high strata are satisfied; otherwise, no substantial influence is made on educational stratification. Lucas (2001) modifies MMI by combining it with the life course perspective (LCP) and proposes an effectively maintained inequality (EMI).

In educational sociology, scholars have made a closer combination between social stratification and education supply. American sociologist Robert Mare proposes the logistic response model, adding time as a control variable. By controlling the changing supply of education opportunities and changes in the occupational and social structure, judgment can be made about trends in unequal education opportunities by evaluating the changing education opportunities of different social classes through interaction (Mare 1980, 1981). Chinese scholars adopt the same method, utilizing data from a 2005 survey of $1 \%$ of the population to compare education opportunities of people born from 1975 to 1979 and those from 1980 to 1985. They find no notable changes in education opportunities between different classes but find that urban-rural inequality was increasing (Li 2014).

\section{Equal education opportunities under policy intervention}

Domestic studies tend to combine the influence of policy intervention and social stratification. Through comparing college student files from Peking University and Suzhou University from 1952 to 2002, Liang et al. (2012) reach the conclusion that promotion of basic education, unified college student recruitment, and establishment of key middle schools have jointly ushered in a silent revolution in diversification of student sources. Hao (2007) conducts a thorough analysis of historical changes of education stratification from a MMI perspective, focusing on the varying effects of policy intervention and the observed influence on education stratification of incidents such as the restoration of the national college entrance exam. Hao concludes that since the reform and opening-up education stratification is assuming many of the characteristics projected in MMI.

The aforementioned research approaches mainly assume a macro- and classical structural perspective tilted toward studies of macropolicies, while microissues, including enrollment cutoffs, education access of youth, and education inequalities are generally neglected.

\section{Process equality under Micropolicy influence: relative age advantages}

We follow the age restrictions in the primary school enrollment system, considering that the rule may bring about relative age effects and the ensuing adaptation crisis and unequal development opportunities. In the 1980s, Roger Barnes notices the issue of relative age and proposed that the Matthew Effect existed in player selection, talent 
classification, and differentiated training (in Gladwell 2009). Through analyzing birthday information of nationally registered track and field athletes, Chinese scholars reach the same conclusion: relative age advantages exist in male and female track and field athletes of different age groups, with a large number of athletes' birthdays found to be close to selection day (cutoff for different age groups, January 1 of the year) and relative age advantages waning as age increases (Wang et al. 2011).

Liu (2006) looks further into the relations between the selection day and excellent athletes with the help of diachronic data, finding that when the selection day of Huangshi Soccer School changes from August 1 to the internationally observed date of January 1st, the birthdays of "genius footballers" change from the August to October and October to December periods to the January to March period.

The effect of relative age on academic performance has drawn attention from some foreign researchers. A Norwegian survey on 15- to 16-year-old youths uses data from Program for International Student Assessment of Organization for Economic Cooperation and Development ${ }^{2}$ (OECD-PISA). The results show that strengths are seen in students born nearer to the cutoff date than those born later, regardless of the family background. The benefits rendered by relative age to youth achievement equal the estimated effect from having a father with a high level of education (Strøm 2004).

An American study looks at age-related rules (e.g., birthday and kindergarten policies) and focuses on the influence of delayed enrollment on learning. Initial performance and later test results are both included in the study; the research finds that a delay of 1 year translated into dramatically improved test results. The study also indicates that delayed schooling is particularly beneficial to at risk children-children living in poverty or with estranged parents, or who are ill (Datar 2006). In addition, the study finds a higher suicide rate among relatively younger students than relatively older ones from the same grade (Thompson et al. 1999).

\section{Equality of education under the coinfluence of macro- and microelements}

Education access during youth and subsequent differences in development is also the subject in what can be termed studies of result equality. Dhuey and Lipscomb (2008) reference surveys conducted with high school students in 1960, 1972, and 1980-1982 on the relations between relative age and leadership. They find that in the same grade and same age, $25 \%$ of students born earlier (the relatively older) have a 4-11\% higher likelihood of taking a leadership position and $5 \%$ more accumulated leadership experience compared to those born later (the relatively younger).

Another research work analyzes correlation of the month of birth and test results of Trends in International Mathematics and Science Study ${ }^{3}$ (TIMSS). It finds that among fourth and eighth graders, students with a higher relative age score better than those with a lower relative age. For students in American 4-year colleges, fewer than $11.6 \%$ are born in a later month of the same year. The difference shows in the millions intrinsically disadvantaged upon entering college, something students born in the middle of the year do not experience (Bedard and Dhuey 2006; Gladwell 2009).In sum, these are the approaches in studies on education access and opportunity equality (Fig 1).

It is evident that studies on the influence of opportunity equality on education access and fairness are abundant, while research on process equality is relatively thin and the 


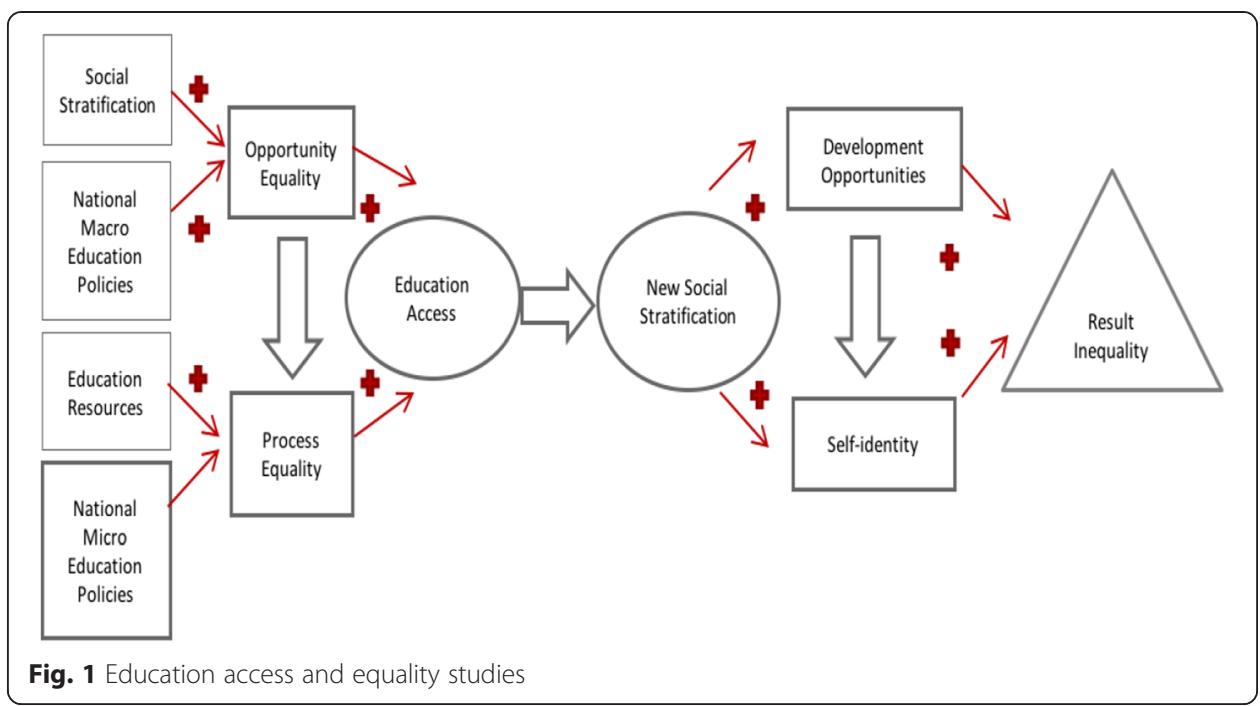

existing works tend to argue from the education resource point of view. This paper aims to provide a strong argument on the influence of micropolicies on process equality, how policies exert influence, and how they affect education access and fairness.

\section{Research approaches and data acquisition}

\section{Data and variable}

Quantitative and qualitative data used in this paper come from the NSSF-sponsored “Studies on Online Games' Influence on Youth Development and Due Guidance." Stratified sampling was carried out in 34 middle schools in Kunming, Yunnan Province, covering 5187 respondents from full-time middle schools and vocational high schools of different districts. Information was collected from five focus groups, one of which was comprised of parents and ten in-depth interviews with interviewees from cities of different levels, including Beijing, Chengdu, Huizhou, Nanchong, and Shenzhen. Interviews lasted from one and a half to two hours. The qualitative and quantitative research subjects were between 13 and 18 years in age.

We adopt demographic variables in the questionnaire for analysis. Based on the primary school enrollment rule, the variables "birth year" and "birth month" are contrasted with the samples' current grade, so as to determine whether the sample are enrolled in school at the prescribed age. As many as 2872 samples were collected from those who entered primary school in accordance with the current rules, accounting for $56.1 \%$ of the total sample. All of the data used in this paper come from this survey.

\section{Analytic strategy}

The central purpose of this paper is to determine, under current enrollment rules, the difference in energy use and development differences during the education of youths born in July and August from those born in other months, particularly those who are born in September and October. Under the current rule-enrollment of children who will be 6 years old before August 31 of the year-based on the distance of this cutoff date to the children's actual birthday, we divide the samples into three birth groups 
based on their relative age: September-October, November-June, and July-August. Given this paper's purpose, the majority of attention was paid to the July-August and September-October groups, with November-June group as the reference.

To see how the enrollment age affects self-identity, academic performance, and development differences, we analyze the behavior and psychology of the youth. Utilizing factor analysis, we summarize information related to temperament, behavior, and psychology. We adopt the approach of "thick analysis" ${ }^{4}$ proposed by Liu $(2010)^{5}$ to study teenagers' personal behavior and time use in their daily life. In establishing the argument for enrollment policies' influence on long-term development of youths, a thick logistic regression model is used. Students from key middle schools are used as dependent variables to establish models, and family background is considered. Given that no questions are designed concerning parental education level, household monthly income and paternal occupation and social standing are used as the main references. In parts of the argument, qualitative materials are used as supplements and analysis of relevant facts is conducted.

\section{Results}

\section{Why is there a July and August pitfall?}

As stated before, our attention is drawn to the July-August group due to their greaterthan-usual online game use. This group is not exceptional in terms of proportion of people who play games, but in the way they use games. Measurements are made for the three groups using the very important variable of game-playing frequency, mainly to highlight the use trap of the July-August group in game use. The results are presented in Table 1.

Among those who never play online games in the semester, the July-August group has the lowest proportion and the September-October group has the highest; among students who play games daily, the July-August group has the largest proportion, which contrasts sharply with the September-October group, with November-June in the mid$\operatorname{dle}\left(x^{2}=12.712, d f=6, p<0.05\right)$.

The duration of each game play, expenses, other dominant behavioral variables, and factor analysis results used to evaluate game dependence were subsequently examined. The differences demonstrated in the game play of the July-August group show that it not merely a data trap but constitutes a "July-August phenomenon." The high frequency and high dependence of the July-August group contrast starkly with the discipline and restraint seen in the September-October group. We believe that the "relative age effect" is evident in the game use of the youth, but it is only the tip of the iceberg of the relative age disadvantages of the July-August group.

Table 1 Game-playing frequency of different birth groups (unit:\%, N=2872)

\begin{tabular}{lcccc}
\hline Frequency & Birth group & & Nov-Dec & Percentage \\
\cline { 2 - 4 } & July-Aug & Sept-Oct & 34.5 & 34.8 \\
\hline No & 33.3 & 37.3 & 19.6 & 19.7 \\
Seldom & 18.8 & 20.9 & 39.9 & 39.7 \\
Frequent & 39.9 & 38.9 & 6.0 & 5.7 \\
Daily & 8.0 & 2.9 & 100.0 & 100.0 \\
Percentage & 100.0 & 100.0 & & \\
\hline
\end{tabular}


Phenomenological analysis of the July-August phenomenon and its institutional origins Before analyzing the differences in the living situation and behavior of birth groups, it is first necessary to introduce what biologists refer to as "ecology." The reason an oak grows to be the tallest in a forest lies in the seed as well as the surrounding environment, other plants included (Gladwell 2009). Ample awareness of different environmental adaptation abilities in students from the same class who are born potentially 12 months apart provides a more comprehensive view of enrollment age restrictions.

In observing the relative age effects in the youths' daily lives, the first consideration is how the effect unfolds. Adaptation is the first challenge for children who are in varying physical development stages when they enter school. It has been proven that in primary school, children with physical advantages tend to demonstrate better adaptation abilities, and consequently gain better access to education and development. Target groups of this study are in a life cycle characterized by a greater school burden than primary school students. Their main daily activity is studying, and learning ability is the major evaluation benchmark by which they are judged. This helps us understand many of the behaviors and mentalities of the youth.

Some studies conclude that differences in adaptation abilities will gradually disappear. We focus on adaptation differences in learning to see whether such differences persist beyond primary school education and in what form. Through summarizing differences in data, we sum up three major aspects of birth groups in terms of adaptability differences: construction of self-identity, academic adaptation crisis, and development opportunities.

\section{Self-identity of those born in July and August}

In Max Weber's view, "purpose" and "means" first come to mind when we consider what makes up a meaningful activity of any kind. We want a thing for "its intrinsic value" or it serves as a "means" to acquire what we want (Weber 2009, 3) (Table 2).

After the control variable "confidence boost from game playing" is added, we see that the July-August group treats game playing more as a way to acquire confidence; in youth groups that deny receiving a confidence boost from game playing, no remarkable frequency difference is noted between the July-August group and the other two groups. Conversely, in groups that believe they get a confidence boost from game playing, the

Table 2 Correlation between confidence acquisition and game-playing frequency(\%)

\begin{tabular}{|c|c|c|c|c|c|c|}
\hline \multirow{2}{*}{\multicolumn{3}{|c|}{$\begin{array}{l}\text { Confidence acquisition and } \\
\text { game-playing frequency }\end{array}$}} & \multicolumn{3}{|c|}{ Month of birth } & \multirow{3}{*}{$\begin{array}{l}\text { Total } \\
(N=2872) \\
42.7\end{array}$} \\
\hline & & & \multirow{2}{*}{$\begin{array}{l}\begin{array}{l}\text { July-August } \\
(N=494)\end{array} \\
40.7\end{array}$} & \multirow{2}{*}{$\begin{array}{l}\text { September-October } \\
(N=497) \\
44.6\end{array}$} & \multirow{2}{*}{$\begin{array}{l}\begin{array}{l}\text { November-June } \\
(N=1961)\end{array} \\
42.7\end{array}$} & \\
\hline No confidence & Game-playing & Never & & & & \\
\hline $\begin{array}{l}\text { boost from } \\
\text { game-plaving }\end{array}$ & $\begin{array}{l}\text { trequency last } \\
\text { semester }\end{array}$ & Seldom & 18.7 & 20.8 & 19.0 & 19.2 \\
\hline & & Frequent & 35.2 & 31.7 & 34.0 & 33.7 \\
\hline & & Daily & 5.5 & 3.0 & 4.4 & 4.3 \\
\hline & Percentage & & 100.0 & 100.0 & 100.0 & 100.0 \\
\hline \multirow{5}{*}{$\begin{array}{l}\text { Confidence boost } \\
\text { from game playing }\end{array}$} & \multirow{4}{*}{$\begin{array}{l}\text { Game-playing } \\
\text { frequency last } \\
\text { semester }\end{array}$} & Never & 5.7 & 10.2 & 3.6 & 5.1 \\
\hline & & Seldom & 19.5 & 21.3 & 22.1 & 21.6 \\
\hline & & Frequent & 57.5 & 65.7 & 62.4 & 62.3 \\
\hline & & Daily & 17.2 & 2.8 & 11.9 & 11.0 \\
\hline & Percentage & & 100.0 & 100.0 & 100.0 & 100.0 \\
\hline
\end{tabular}


gaming frequency of the July-August group sees a dramatic increase to $17.2 \%$, contrasted with a mere $2.8 \%$ in the September to October group $\left(X^{2}=17.992, d f=6, P<0.01\right)$. Moreover, the percentage of the July-August group who experience overly long game duration (over $7 \mathrm{~h} / \mathrm{t}$ ) believing they would receive a confidence boost from games $(13.8 \%)$ is far higher than that of the September-October group (5.7\%) and the November-June group (6.8\%). This difference is shown only after the confidence boost variable is added $\left(X^{2}=26.127, d f=8, P<0.001\right)$.

Girls score lower than boys in every index in online game use. However, after the variable "I think talent is better shown in the game world" is added, the gaming frequency of the July-August group records a substantial rise $\left(X^{2}=19.495, d f=6, P<0.01\right)$ as compared with the other two groups, while there is no notable change in male groups.

During in-depth interviews, a boy who gave up online games due to academic pressure revealed, "After quitting for a while, my confidence is gone" (NC01, male, 17). NC01 is a grade two student from a key class of a key high school. His strongest emotion about reduced game play was the loss of confidence.

We believe that confidence acquisition makes up a main cause for game play for the July-August group. During the process of constructing self-identity, confidence building constitutes an important component of youths' socialization. Due to its relative age advantage, the September-October group can better adapt to school life, obtain more attention and development opportunities, and have more means to acquire confidence, and therefore are less dependent on online games.

One important way of constructing self-identity is to determine what kind of person one wants to be. Generally speaking, youth whose fathers work in government agencies or take leadership positions tend to plan for their future earlier. This is more evident in the July-August group, especially among girls $\left(X^{2}=9.079, d f=2, P<0.01\right)$, while the September-October group has the lowest ratio of students planning their future. A commonly held opinion is that those who set goals earlier are more likely to succeed, but our statistics indicate that the September-October group better adapts to the environment are healthier and focuses on here and now rather than compensate for the adaptability crisis with fantasies.

A set of data proves to be persuasive. Among girls with no plans for a future career, the July-August group exhibits the highest ratio of game playing at $44.9 \%$, much higher than the $38.2 \%$ of the September-October group and the $39.5 \%$ of the November-June group $\left(X^{2}=13.328, d f=6, P<0.05\right)$. Even among girls with clear career goals, those who were born between July and August manifest a lack of self-control.

\section{The academic adaptation crisis of the July-August group}

To study the varying adaptation abilities of youth in daily life, proper variables must be selected. We believe that research on "energy use mode" reflects different approaches to social time and time capital thus generated. An invasion of the work space into personal life (space for social life) brings out periodicity of social time, i.e., periodicity of energy use, meaning energy excess, energy deficiency, and energy surplus in individual's social time (Liu 2007). We believe that time allocation at the workplace (school) is a partial reflection of one's living situation and behavioral and psychological logic formed in response to the situation. It will help us better see the differences in the three groups in adapting to academic pressure. 
Considering the age and daily activities of the surveyed students, we mainly focus on the different time allocation for the following activities of the three groups during schooldays and holidays: ${ }^{6}$ (a) sleep, (b) weekly tutoring, (c) entertainment, (d) sports, and (e) homework. Before examining the differences, we look at how students evaluate their "study enthusiasm." ${ }^{77}$ No notable differences are seen. Statistically speaking, time allocation is not influenced by personal predilection.

After examining the mean score of time allocation, we find notable differences in time allocated for tutoring during holidays between the July-August group and the other two groups $(F=4.25, P<0.05)$, who exhibit no differences between themselves (Table 3).

Tutoring during holidays usually denotes two scenarios: one where recreation time is sacrificed for subjects performed poorly to make up for the adaptation crisis; and the other one, in which future lessons are previewed for better adaptation in the new semester. Whichever reason is the leading cause, the willingness to spend extra time reflects inadequate adaptation in daily study to some extent. Correlated to this is the efficient use of class time. We therefore examine "confidence in efficient use of class time." The results are shown in Table 4.

To a certain degree, the results shown in Fig. 4 indicate a greater adaptation crisis in the July-August group, which is especially noticeable in the middle school period $\left(X^{2}=9.368, d f=2, P<0.01\right.$, the ratio of students reporting efficient use of time is 3.5 \% lower than the September-October group and $9.9 \%$ lower than the November-June group). A greater time allocated to tutoring during holidays by the July-August group compensates for poor adaptation. We consequently conduct OLS regression analysis with tutoring time during holidays as a dependent variable to further study the varying characteristics of the three birth groups in academic adaptation, taking multiple factors into account (Table 5).

With model analysis, we subsequently created Figs. 2 and 3. We have the following findings.

Table 3 Comparison of mean scores and standard deviation of time spent on weekly tutoring during holidays $(N=2313)$

\begin{tabular}{llll}
\hline School type & Birth month & \multicolumn{2}{l}{ Time spent on tutoring per week during holidays(h) } \\
\cline { 3 - 4 } & & Male & Female \\
\hline Key middle schools & July-August & $1.96(2.25)$ & $2.44(2.33)$ \\
& September-October & $2.00(2.21)$ & $1.97(1.96)$ \\
& November-June & $2.07(2.24)$ & $2.13(2.28)$ \\
& Total & $2.04(2.23)$ & $2.16(2.25)$ \\
Ordinary middle schools & July-August & $2.41(2.30)$ & $2.09(2.33)$ \\
& September-October & $1.93(2.29)$ & $1.35(1.65)$ \\
& November-June & $1.73(2.03)$ & $1.91(2.08)$ \\
& Total & $1.86(2.13)$ & $1.86(2.07)$ \\
Total & July-August & $2.24(2.28)$ & $2.22(2.23)$ \\
& September-October & $1.96(2.25)$ & $1.57(1.79)$ \\
& November-June & $1.86(2.12)$ & $1.99(2.15)$ \\
& Total & $1.93(2.17)$ & $1.97(2.14)$ \\
\hline
\end{tabular}


Table 4 Proportion of youth reporting efficient use of class time $(N=2313)$

\begin{tabular}{lllllll}
\hline Educational stage & & \multicolumn{2}{l}{ Birth month } & Total (\%) \\
\cline { 4 - 6 } & & & July-Aug & Sept-Oct & Nov-Jun & \\
\hline Middle school & Efficient use of class time & No(\%) & 64.4 & 60.9 & 54.5 & 57.1 \\
& & Yes(\%) & 35.6 & 39.1 & 45.5 & 42.9 \\
& Total & & 100.0 & 100.0 & 100.0 & 100.0 \\
High school & Efficient use of class time & No(\%) & 60.6 & 62.1 & 60.3 & 60.6 \\
& & Yes(\%) & 39.4 & 37.9 & 39.7 & 39.4 \\
& \multirow{2}{*}{ Total } & & 100.0 & 100.0 & 100.0 & 100.0 \\
& Effal & No(\%) & 63.3 & 61.4 & 56.7 & 58.4 \\
& & Yes(\%) & 36.7 & 38.6 & 43.3 & 41.6 \\
& Total & & 100.0 & 100.0 & 100.0 & 100.0 \\
\hline
\end{tabular}

(1) Regardless of gender and school type, the July-August group spends more time and energy on holiday tutoring than other groups, with a maximum of 99.9-133.2 min of extra time spent.

(2) There is a positive correlation for teenage boys between the extra time spent on studying and how bad their current school is perceived for their future development. In contrast, the correlation is negative for girls, which helps explain a

Table 5 OLS regression model of weekly tutoring time of youth during summer and winter holidays $(N=2313)$

\begin{tabular}{|c|c|c|c|}
\hline Independent variables & Unstandardized regression coefficient & SE of $B$ & Sig. \\
\hline (Constant) & $3.391^{* * *}$ & 693 & .000 \\
\hline Male & -.233 & .127 & .066 \\
\hline Birth month & -.923 & .531 & .083 \\
\hline Birth month ${ }^{2}$ & .221 & .128 & .085 \\
\hline School type ${ }^{4}$ & -.001 & .001 & .227 \\
\hline Male $\times$ school type ${ }^{4} \times$ birth month & $.003^{*}$ & .001 & .021 \\
\hline Male $\times$ school type ${ }^{4} \times$ birth month ${ }^{2}$ & $-.001^{*}$ & .000 & .017 \\
\hline Family monthly income(yuan) & -.120 & .074 & .104 \\
\hline Grade & $-.889^{*}$ & .393 & .024 \\
\hline Grade $^{2}$ & .115 & .066 & .083 \\
\hline Grade $\times$ family monthly income & $.198^{* * *}$ & .061 & .001 \\
\hline Grade $^{2} \times$ family monthly income & $-.034^{* * *}$ & .010 & .001 \\
\hline Temperament_active learner & $201^{* * *}$ & .063 & .001 \\
\hline Temperament—extroverted & $.182^{* *}$ & .070 & .010 \\
\hline Temperament_-self-disciplined & $-.314^{* * *}$ & .062 & .000 \\
\hline Only child & .174 & .091 & .056 \\
\hline$R^{2}$ & .070 & & \\
\hline Adjusted $R^{2}$ & .064 & & \\
\hline Significance level of model & .000 & & \\
\hline
\end{tabular}

Note: (i)Tutoring time is obtained from the question "Average tutoring time during summer and winter holidays"; data is subsequently standardized. Temperament factor is obtained through scale of attitude and behavior; (ii) based on Chinese high school education resource allocation, we investigated different schools of the surveyed teenagers. We categorized education resource allocation as $1=$ key class of key school; $2=$ ordinary class of key school; $3=$ key class of ordinary school; 4 = ordinary class of ordinary school. Now, the school type is no longer a fixed nominal level variable but an ordinal level variable. Thus, we could conduct data conversion and regression ${ }^{*} P<0.05,{ }^{* *} P<0.01$, ${ }^{* * *} P<0.001$ 


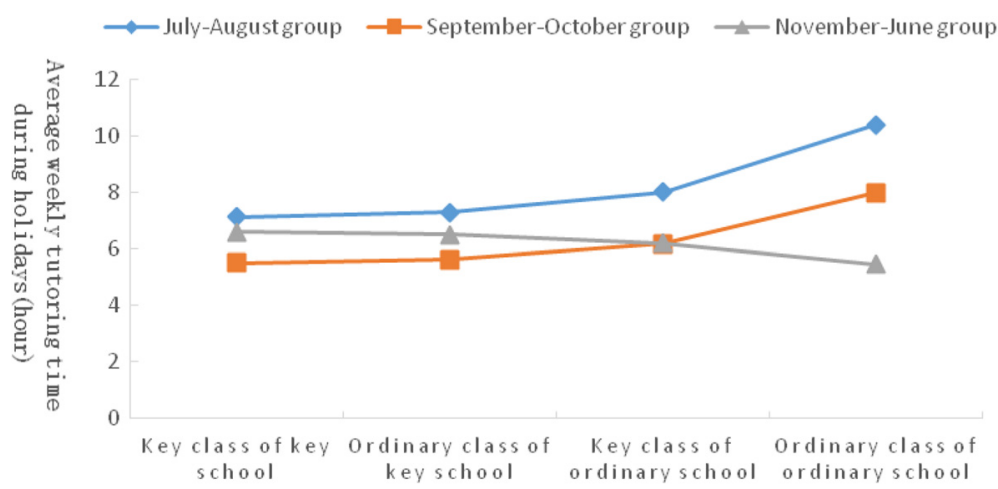

Fig. 2 OLS regression model of tutoring time during holidays of teenage boys from different school types and birth months

long-standing misconception: That girls tend to lose competitiveness in higher stages of learning is not due to their limited intellectual ability but to the fact that boys are simply putting more time and energy into study.

Comparatively speaking, students from the July-August group are more passive in face of academic pressure. In key middle schools, they are willing to devote more time in order to compete with fellow students. We examine the time use of the three birth groups from vocational schools and find a completely opposite trend of premature quitting on study, another case where the environment influences how one manages time and energy.

\section{The insurmountable "July-August" pitfall}

As mentioned above, studies on education access and equality of education opportunities mainly focus on the socioeconomic status of the family, macroeducational policies, and supply of educational resources. Thomas points out that the records of individual development must be used to make studies more scientific so that personal life, as a measure of general social influence, can be used to measure how a particular institution affects the formation of disposition and personal life. Therefore, this study examines if age restriction, as a micropolicy, has any impact on education access during the basic educational stage. In other words, it explores whether the July-August group of students suffers from relative disadvantages in terms of access to premium education

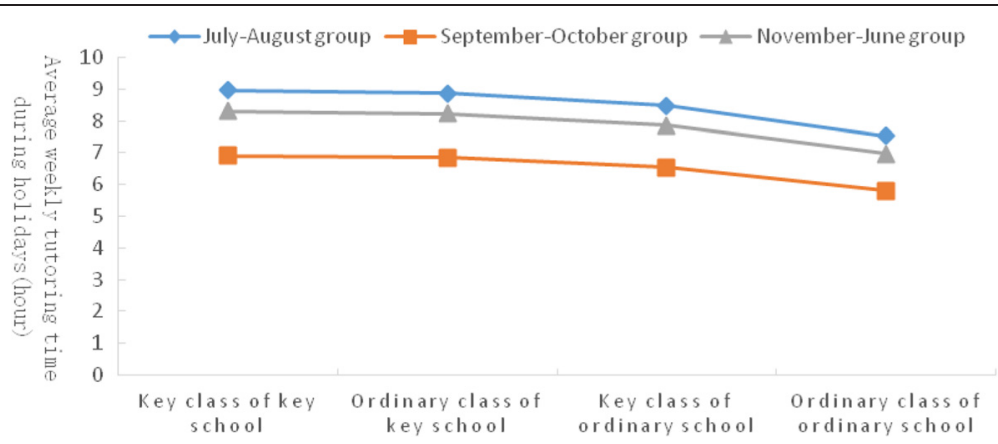

Fig. 3 OLS regression model of tutoring time during holidays of teenage girls from different school types and birth months 
opportunities in middle and high schools compared with the other groups, particularly the September-October group, i.e., whether the relative age effect accumulates.

The samples are taken from high schools. Although this means that there is data of adaptability during primary school, it helps us look at the larger process, follow students as they attend schools of different status, and examine opportunity equality at the basic educational stage. Admission to key middle schools is used as the dependent variable, family's monthly income is used to represent influence of family's socioeconomic status, and occupation and status of fathers along with other variables are controlled to inspect the differences of different birth groups in their access to better education resources and development opportunities. Meanwhile, the interaction effects between birth month and variables are explored (Table 6).

From the model and Figs. 4 and 5, we can conclude the following points:

(1) Family socioeconomic status plays an essential role in youths' access to better education resources and opportunities, with girls more reliant on family background. However, the "July-August effect" is such that family income level, occupation, and status ${ }^{8}$ combined cannot inhibit its influence. Therefore, it can be said that to a certain extent, the "July-August pitfall" is insurmountable.

(2) Regardless of gender and family income, the September-October group is more likely to enter key middle schools, whereas students born in July and August are the least likely to do so.

(3)For the July-August group, boys are more heavily influenced by enrollment polices. As shown in Fig. 5, despite the large differences between girls from the July-August

Table 6 Factors influencing access to premium education resources (logistic model) $(N=2872)$

\begin{tabular}{|c|c|c|}
\hline Independent variables & $B$ & Sig. \\
\hline Male & .180 & .317 \\
\hline Birth month & $1.422^{* *}$ & .010 \\
\hline Birth month ${ }^{2}$ & $-.359^{* *}$ & .007 \\
\hline Family monthly income ${ }^{3}$ (yuan) & $.003^{*}$ & .038 \\
\hline Family monthly income ${ }^{4}$ (yuan) & .000 & .109 \\
\hline Male $\times$ birth month $\times$ family monthly income ${ }^{3}$ & $-.008^{*}$ & .035 \\
\hline Male $\times$ birth month ${ }^{2} \times$ family monthly income ${ }^{3}$ & $.003^{*}$ & .038 \\
\hline Male $\times$ birth month $\times$ family monthly income ${ }^{4}$ & $.001^{*}$ & .039 \\
\hline Male $\times$ birth month ${ }^{2} \times$ family monthly income ${ }^{4}$ & $.000^{*}$ & .042 \\
\hline Only child & .015 & .951 \\
\hline Cube of age & $.000^{* * *}$ & .000 \\
\hline Teacher-student relationship & $-.520^{*}$ & .025 \\
\hline Teacher-student relationship ${ }^{3}$ & .071 & .135 \\
\hline Only child $\times$ age $^{3} \times$ teacher-student relationship & $.000^{* * *}$ & .001 \\
\hline Only child $\times$ age $^{3} \times$ teacher-student relationship ${ }^{2}$ & $.000^{* *}$ & .003 \\
\hline Paternal occupation(government agencies or leadership position) & $327^{* * *}$ & .001 \\
\hline Constant & -.685 & .278 \\
\hline -2loglikelihood & 3198.717 & \\
\hline$R^{2}$ & .128 & \\
\hline$N$ & 2872 & \\
\hline
\end{tabular}




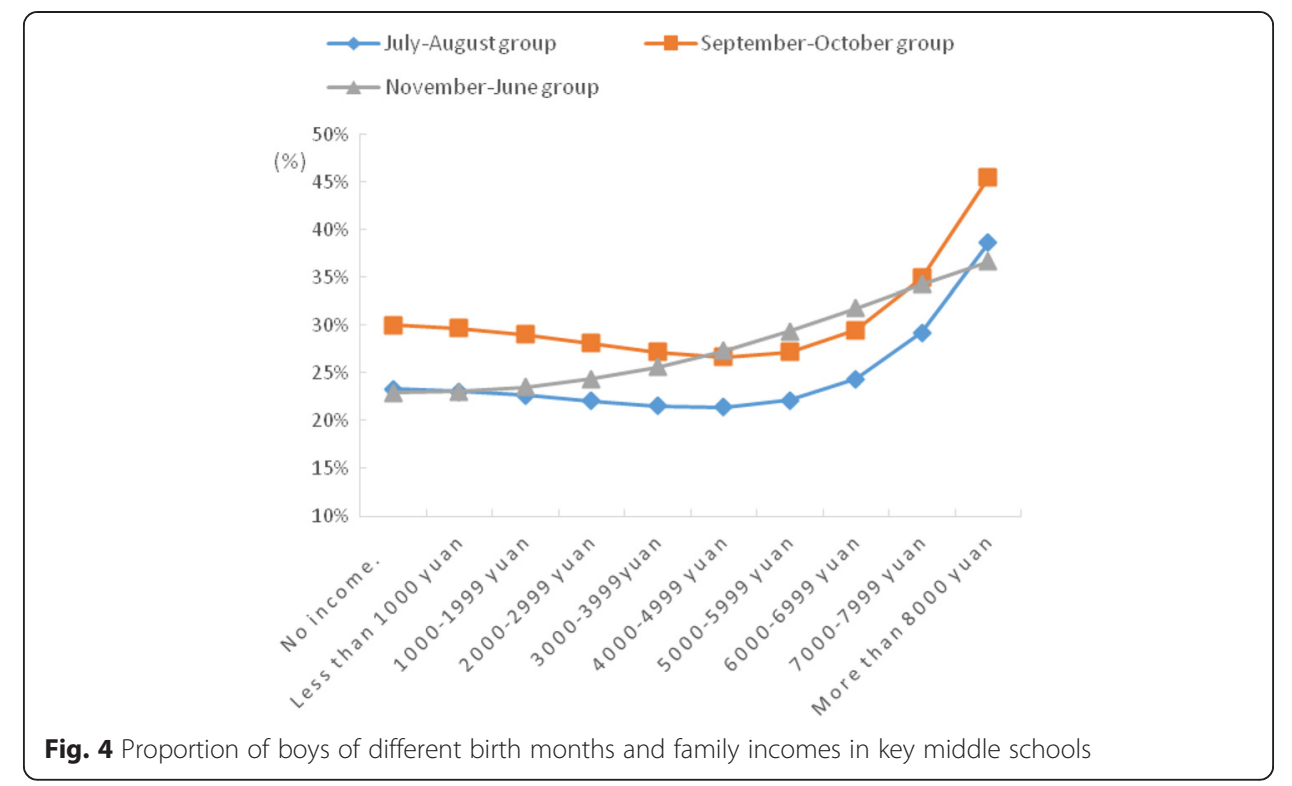

group and those from the September-October group, the July-August group has an equal chance of being admitted to key middle schools as the November-June group and, when family income is equal, an even higher likelihood. In contrast, large differences exist among boys.

(4)Boys from a humble background are more likely to succeed than their female counterparts and when the socioeconomic status of the family is high enough, social and cultural capital coming from within the family can help flatten the difference between the July-August group and other groups.

Supplemental data prove the validity of our generational study on those born in the 1990s. Of the $22.3 \%$ who attend key universities, the July-August group takes up only $17.6 \%(P<0.05)$, and the September-October group takes up the largest share. Domestic studies have already proven that key middle schools constitute the main

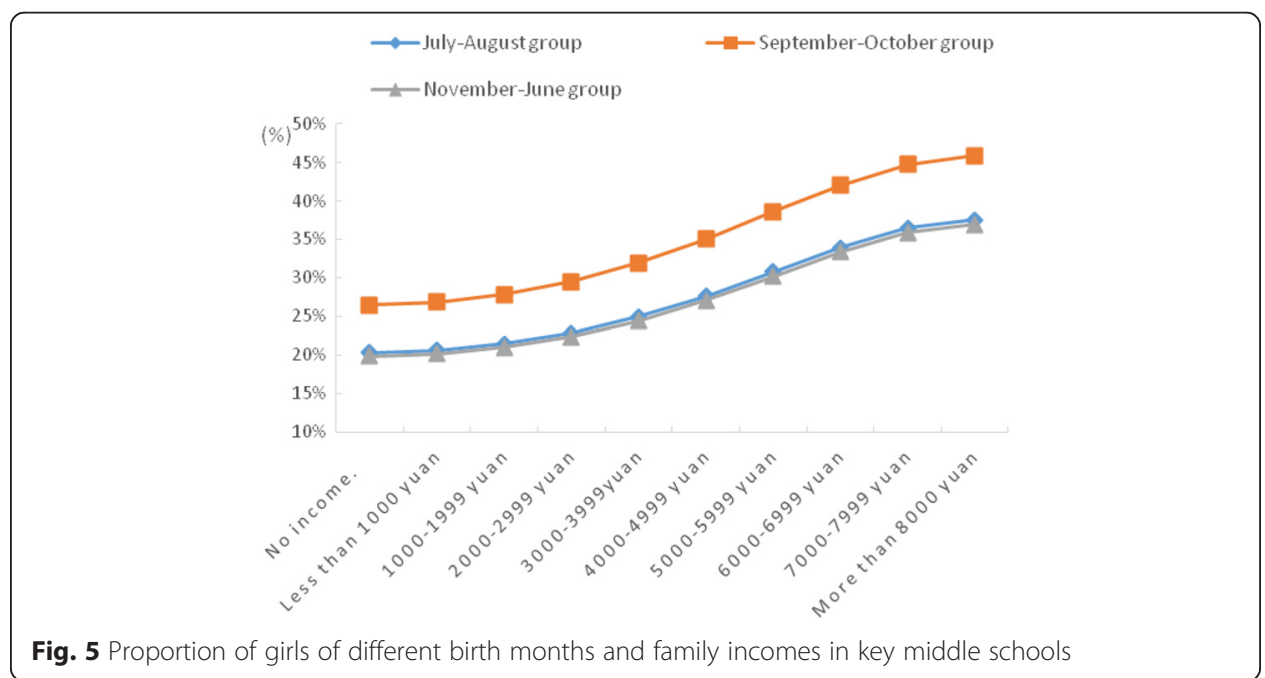


source of students for elite universities, and that the poorer the region is, the more important it is to be admitted to key middle schools (Liang et al. 2012).

In sum, youth born in July and August exhibit notable relative age disadvantages in academic adaptation and access to developmental opportunities and suffer from accumulated effects. These effects have institutional origins and can be summarized as follows, based on how they unfold and exert impact. First, age restrictions under the current primary education system cause institutional enrollment disadvantages that in turn lead to insufficient energy in the July-August group and ultimately an adaptation crisis. Second, due to institutional and environmental reasons, students born in July and August are neglected and their construction of self-identity and confidence building are eclipsed as a result. Third, differences occurring at enrollment and subsequent neglect accumulate and continue to influence students at different stages of education, entrance exams institutionally eliminate children with weaker adaptability. Children born in July and August have their access to premium education severely compromised.

\section{Conclusions and suggestions}

\section{Conclusions}

This paper studies youth born in July and August who enroll in schools in accordance with national regulations to see whether they are put at a disadvantage induced by poor adaptability, how such disadvantages manifest in daily life, and how such micropolicy arrangements cause educational inequality for the July-August group. We hold the view that the enrollment cutoffs placed on primary school education do have a major effect on the lives and academic performance of youth born in July and August. This micropolicy brings inequality in access to developmental opportunities and education resources, causing adaptation-induced disadvantages, institutional neglect, and institutional elimination at entrance exams.

Our specific conclusions are as follows. First, due to differences in physical development, youth born nearest to the cutoff date in July and August falls victim to the relative age effect and adaptation crisis as compared with youth of other birth groups. Specifically, their disadvantages are tangible in three aspects: construction of selfidentity, academic adaptation crisis, and development opportunities. The disadvantages in the construction of self-identity comprise: (1) greater reliance on online games to gain confidence and praise; and (2) more self-illusion in those born in July and August to compensate for adaptation crises in real life. The disadvantages in academic adaptation stem from the fact that youth born in July and August experience energy deficiency, adaptation crisis, and inefficient use of class time during study that results in the necessity of devoting extra time, taking 99.9-133.2 more minutes for tutoring per week during holidays than other students.

In terms of development opportunities, the relative age effect accumulates, ultimately influencing the July-August group's access to premium education resources. The group has a 16.7-22.8 \% lower chance of being admitted to key middle schools and a 54.2$60.8 \%{ }^{9}$ higher chance of going to occupational schools, particularly for boys. The relative age effect can only be subtly inhibited by the sufficiently high socioeconomic status of the family. Generally speaking, the July-August pitfall is almost insurmountable. 
In addition, due to the slower physical development of boys during adolescence, the relative age effect and its accumulative effect have a greater influence on boys. This difference exists not only in academic terms. A male student born in August (BJ10, male, 22), after entering into master's level of education, looks back at his different stages of his education and observes: "Someone like me is seldom assigned an important job or named a leader. Although I am the most active one, in each stage of education, I'm treated more like a 'mascot.' People take their opinions from sedate and modest persons instead of me." This feeling resonates with many boys born in July and August, who experience a $1.5 \% 6.5$ percent lower chance of being an elected holder of a major position in their class (Fig 6).

\section{Suggestions for adjustment of the primary school cutoff date}

As mentioned in the introduction, parents and society at large are requesting that age restrictions be loosened in order to allow enrollment of children about to turn six. This would humanize the policies and avert the emergence of a "grey area." Taking into consideration other countries' relevant policies and this paper's conclusions, the following suggestions are offered for age restrictions and daily teaching and management.

First, setting up a system in which several enrollments take place per year, or allowing students to choose when to enroll. Youth born within the same time range are to be assigned to the same class to reduce unequal competition.

Second, implementing the practice of evaluating enrollment preparedness. The optimal enrollment date will be recommended by specialized evaluation agencies of education departments.

Third, opening up enrollment options for boys. Boys born near the cutoff date should be recommended to put off enrollment.

Fourth, more attention should be given to relatively young students. Through daily interaction, parents and teachers should help these students better adapt to schoolwork and build confidence.

Fifth, parents should be duly educated to not hasten enrollment but instead select the proper enrollment time based on their child's development for the sake of long-term benefits.

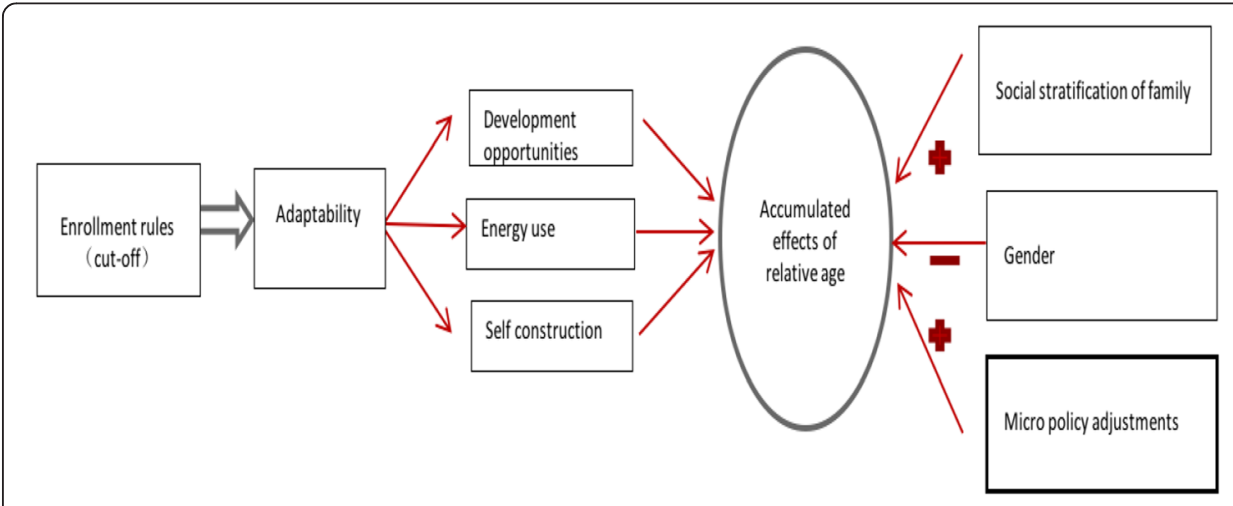

Fig. 6 How enrollment policies influence equal access to education 
Taken in themselves, statistics are nothing more than symptoms of unknown causal processes. A social institution can be understood and modified only if we do not limit ourselves to the study of its formal organization but also to analyze the ways in which it appears in the personal experience of various members of the group and follow the influence that it has on their lives (Thomas 1988). When it comes to the distribution of education resources, there are urban-rural and class-based disparities. Better data analysis and research, coupled with correct judgment of policy trends and influence will contribute effectively to the development of education policies and education fairness.

Different from many of the macrofactors influencing education access that are force majeure, the relative age effect caused by age restraints can be diminished by policy adjustments. Opening up age restrictions poses a test for governments and may cause concerns among parents, but it is essential that an optimal solution is found that will spare youth from negative influences caused by artificially set up cutoffs.

There are two shortcomings concerning the data collection in this study. First, the 14,558 samples collected from 13- to 18-year-olds in a stratified and staged manner from first to fifth tier cities via Tencent platform were not strictly selected as is done in Kunming data and therefore not as credible and valid. A conclusion that is applicable nationwide thus cannot be reached. Second, primary school students are not included in the sampling, and therefore, examination of the group most susceptible to adaptation crisis is missing. The findings of this paper do not convince us that the issue is more worrisome than we consider it to be. More extensive and comprehensive data collection and statistical study is needed for decision making.

Micropolicies may not seem as pressing or relevant as macropolicies, but they influence people's future prospects. During policy making, long-term and latent influences rather than short-term and immediate concerns should be given higher priority. More wisdom and focus is needed in policy terms so that a "Pareto optimality" solution can emerge from the static or dynamic power struggle in order to maximize education opportunities for all.

\section{Endnotes}

${ }^{1}$ Strictly speaking, these two approaches do not belong to a purely macrosphere. However, when talking about youth's education access, we consider family background to be a stable ascribed factor uncontrolled by the youth and subject to macrosocial structure, and therefore include it in the macro study category.

${ }^{2}$ An evaluation of reading, math, and scientific capacities for 15 -year olds who are about to complete compulsory education.

${ }^{3} \mathrm{~A}$ test of mathematics and science amplitude taken quadrennially by youth worldwide.

${ }^{4}$ Thick analysis is inspired by the concept "thick description" (originally from Gilbert Ryle) mentioned in The Interpretation of Culture by anthropologist Geertz (1999). With thick analysis, logical correlation is sought among variables during quantitative analysis. Logical structure and chain of influence among variables is examined from different dimensions; the complex and real cause-and-effect relationship and development of things is exhibited. Human diversity and real-life scenarios are taken into account. Qualitative mentality is applied to quantitative analysis due to the special nature of the research subject. Describing "thick quantitative analysis" in quantitative terms includes 
nonlinear functions treated as independent variables with complex interactions. Such analysis helps provide an in-depth description of the laws of society, not subjective assumptions of researchers.

${ }^{5}$ This method was first introduced in the keynote speech titled "Reflection on the Methodology of Communication Studies" in The 8th Chinese Internet Research Conference (Peking University, June 29-30, 2010).

${ }^{6}$ Considering the different lifestyles of students in full-time ordinary middle schools and those in occupational middle schools, this part of the analysis focuses on youth in full-time, ordinary middle schools.

${ }^{7}$ In factor analysis of youths' daily activities and mentalities, the following items are combined as the same factor: "I answer questions in class voluntarily"; "I make efficient use of class time"; "Teachers ask me questions during class frequently"; "I'm satisfied with my study"; "I discuss school issues with classmates frequently." We term such items factors of "learning enthusiasm."

${ }^{8}$ Parental occupation and identity is the result of recoding after income level was considered. Fathers who work in government agencies or take a leadership position are coded 1; they include civil servants, staff in public institutions including teachers at primary and middle schools, lawyers, college teachers, CEOs, and other professionals holding high social status. The rest are coded 0 , including workers, farmers, migrant workers, owners of individual businesses, and employees of privately run businesses.

${ }^{9}$ We established models to analyze the likelihood of each birth group entering occupational middle schools. Due to word limits, only the conclusions are listed here for reference.

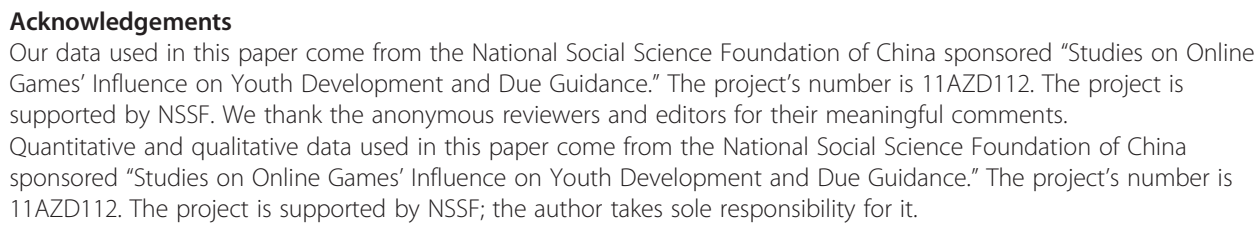

Our data used in this paper come from the National Social Science Foundation of China sponsored "Studies on Online Games' Influence on Youth Development and Due Guidance." The project's number is 11AZD112. The project is supported by NSSF. We thank the anonymous reviewers and editors for their meaningful comments. Quantitative and qualitative data used in this paper come from the National Social Science Foundation of China sponsored "Studies on Online Games' Influence on Youth Development and Due Guidance." The project's number is 11AZD112. The project is supported by NSSF; the author takes sole responsibility for it.

\section{Authors' contributions}

LDH built up the framework of the study, conducted the research design, and performed the main statistical analysis. $\mathrm{LXL}$ carried out the research by contributing to the statistical analysis and literature review. The manuscript was drafted and approved by the authors together.

\section{Competing interests}

The authors declare that they have no competing interests.

\section{Author details}

${ }^{1}$ Peking University School of New Media, Peking University, No.5 Yiheyuan Road Haidian District, Beijing 100871, People's Republic of China. ${ }^{2}$ Peking University School of Journalism and Communication, Peking University, No.5 Yiheyuan Road Haidian District, Beijing 100871, People's Republic of China.

Received: 16 May 2016 Accepted: 15 August 2016

Published online: 08 September 2016

\section{References}

Bedard, Kelly, and Elizabeth Dhuey. 2006. The persistence of early childhood maturity: international evidence of long-run age effects. The Quarterly Journal of Economics 121(4): 1437-1472.

Bourdieu, P., and J-C Passeron. 2002. The inheritors: French students and their relation to culture. Trans. Xing Chaoke. Beijing: The Commercial Press.

Datar, Ashlesha. 2006. Does delaying kindergarten entrance give children a head start?". Economics of Education Review 25: 43-62.

Dhuey, Elizabeth, and Stephen Lipscomb. 2008. What makes a leader? Relative age and high school leadership. Economics of Education Review 27: 173-183. 
Hao, Dahai. 2007. A study of educational disparity in urban China (1949-2003). Social Sciences in China 6: 94-107.

Li, Yu. 2006. Institutional change and educational inequality: Mechanisms of educational stratification in urban China (1966-2003). Social Sciences in China 4: 97-109.

Li, Chunling. 2014. Educational experience and inequality of opportunity among the post-80s generation-With comments on the silent revolution. Social Sciences in China 4: 66-77.

$\mathrm{Li}, \mathrm{TaO}$, and Ke Li. 2013. A few days birth late leads to a year's delayed enrollment: should enrollment age restrictions be loosened. (http://news.cnwest.com/content/2013-05/22/content_9297663.htm).

Liang, Chen, Zhongqing Li, Hao Zhang, Lan Li, Danqing Ruan, Wenlin Kang, and Shanhua Yang. 2012. Silent revolution: The social origins of Peking University and Soochow University Undergraduates, 1952-2002. Social Sciences in China 1: 98-118.

Liu, Jingming. 2006. Expansion of higher education in China and inequality in entrance opportunities: 1978-2003. Chinese Journal of Sociology 3: 158-179.

Liu, Weimin. 2006. Study about effect of age factor in identification talent of adolescent soccer players. Journal of Hubei Normal University (Natural Science) 26(1): 30-34.

Liu, Dehuan. 2007. Age: social time in social space. Beijing: China Commerce and Industry United Press.

Lucas, S.R. 2001. Effectively maintained inequality: education transitions, track mobility, and social background effects. American Journal of Sociology 106(6): 1642-1690.

Mare, R.D. 1980. Social background and school continuation decisions. Journal of the American Statistical Association 75: 295-305.

Mare, R.D. 1981. Change and stability in educational stratification. American Sociological Review 46: 72-87.

Raftery, A.E., and M. Hout. 1993. Maximally maintained inequality: Expansion, reform and opportunity in Irish education 1921-1975. Sociology of Education 66: 41-62.

Strøm, Bjarne. 2004. Student achievement and birthday effects. Paper prepared for presentation at the CESifo-Harvard University/PEPG Conference on "Schooling and Human Capital in the Global Economy: Revisiting the Equity-Efficiency Quandary," Dragvoll, Norway.

Thomas, William. 1988. The unadjusted girl—with cases and stand points for analysis. Trans. Qian Jun et al. Shandong: Shandong Renmin Press.

Thompson, Angus H., Roger H. Barnsley, and Ronald J. Dyck. 1999. A new factor in youth suicide: The relative age effect. The Canadian Journal of Psychiatry 44: 82-85.

Wang, Xiaolu, Shaolan Liang, Jiye Wang, Jingjing Dong, and Mei Xu. 2011. Analysis of characteristics and causes of relative age distribution of top youth athletes in China. Progress in Modern Biomedicine 4: 703-706.

Weber, Max. 2009. Methodology of Social Sciences. Trans. Li Qiuling. Tianwei, Beijing: China Renmin University Press.

Zhang Xuebin, Leiyu. 2015. What are capricorns to do when age restrictions are loosened? Nanfang Daily, February 12.

Zhao, Yandong, and Yanbi Hong. 2012. Social capital in educational attainment: The perspectives of network resource and social closure. Sociological Studies 5: 47-68.

\section{Submit your manuscript to a SpringerOpen ${ }^{\circ}$ journal and benefit from:}

- Convenient online submission

Rigorous peer review

- Immediate publication on acceptance

- Open access: articles freely available online

- High visibility within the field

- Retaining the copyright to your article 